\title{
Access Measures Do Not Reflect Actual Access in Urology Clinics
}

\author{
Blake D. Hamilton, David Ray, Staci Taufer, David Webber, Brent W. Snow \\ Division of Urology, Department of Surgery, School of Medicine, University of Utah, Salt Lake City, USA \\ Email: blake.hamilton@hsc.utah.edu, david.ray@hsc.utah.edu, staci.taufer@hsc.utah.edu, david.webber@hsc.utah.edu, \\ brent.snow@hsc.utah.edu
}

How to cite this paper: Hamilton, B.D., Ray, D., Taufer, S., Webber, D. and Snow, B.W. (2017) Access Measures Do Not Reflect Actual Access in Urology Clinics. Open Journal of Urology, 7, 1-8. http://dx.doi.org/10.4236/oju.2017.71001

Received: November 19, 2016

Accepted: January 3, 2017

Published: January 6, 2017

Copyright $\odot 2017$ by authors and Scientific Research Publishing Inc. This work is licensed under the Creative Commons Attribution International License (CC BY 4.0).

http://creativecommons.org/licenses/by/4.0/

\begin{abstract}
Introduction: Improvement in new patient access to urologic care is important and is increasingly measured as a reflection of practice quality. Two broad categories affect patient access: provider issues and patient preferences. We chose to study the previously unreported patient choices that affect access delays between the time a urology appointment is requested and the urology appointment itself. Methods: A 3-week real time telephone survey was conducted with callers seeking a urology appointment. If the callers did not choose the first available appointment, they were questioned as to why they did not. This data was then compared to a 3-month access delay graph noting the number of new patients offered each day. Results: Adult and pediatric urologic clinics were evaluated separately. For adult clinics, $14 \%$ of patients chose not to accept the first available appointments and 5\% sought urologic care elsewhere. For pediatric clinics, $44 \%$ delayed access beyond the first available appointment. Of these, $26 \%$ were asked by the physician to delay in order to time appointments with imaging studies on the same day, or were advised to wait longer because of the nature of the patient's diagnosis. Parents' choice delayed $18 \%$ of the appointments beyond the first available appointment. Discussion: These data reveal that about $85 \%$ of new patient access falls within the provider's control. The other $15 \%$ of delays rest on the preferences of the patients. These decisions significantly skew the access delay data that is increasingly being used to measure the quality of a urology practice.
\end{abstract}

\section{Keywords}

Pediatric Urology, General Urology

\section{Introduction}

Prompt access for patients to see providers in adult and pediatric urology is a timely issue and needs significant attention and thoughtful adjustments to make 
improvements [1] [2] [3] [4]. Increasingly, measuring the delay in access to care is being used as a measure of quality of medical care. Many institutions, including the University of Utah, are looking to improve access measures-specifically new patient access-to improve the performance of their ambulatory services [5] [6] [7] [8] [9]. Historically, access to medical care has been measured in a variety of ways. Berwick described the " $3^{\text {rd }}$ next available" appointment [10] which became the industry standard for many years. More recently, defining access as "average schedule lag" has arisen from the annual "Patient Access Symposium". Even more recently, University Hospital Consortium (UHC), revised their metric to median (rather than mean) schedule lag, presumably to reduce the impact of outliers. UHC has also recently announced the inclusion of this metric in their 10 quality metrics for assessing ambulatory services [11]. With all of this fluctuation, it is critical for providers in all fields, including urology, to better understand the factors that affect access to care.

This research effort focuses on "new patient" access to ambulatory urologic care. In an ongoing effort to improve our new patient access, we sought to understand why new urologic patients do not choose the first available appointment. Such patients who consciously choose an appointment time later than the first available appointment have reasons for doing so, but that choice skews the above-mentioned metrics. We have made a concerted effort to improve new patient access, attempting to shorten the time between the initial phone call and the appropriate urologic clinic visit. We wanted to understand 1) what part of new patient access is within the provider's control and, correspondingly, what part is due to patient choice, and 2) why a patient would choose to wait longer than the first available appointment.

\section{Materials and Methods}

At the University of Utah we have adult and pediatric urology clinics that are separate. Our adult urology clinic is comprised of 4 urologists, 1 nurse practitioner (APRN), and 2 physician assistants (PA), with subspecialty training that includes laparoscopy, endourology, reconstruction, men's sexual health and urodynamics (our cancer-specific urologists practice in a separate facility). The majority of the patients come from the metropolitan area within 50 miles, however, around $30 \%$ of patients come from the large regional catchment area that is formed by a roughly 500 mile radius from Salt Lake City, Utah. To lessen the number of office visits for these traveling patients, it is a high priority to obtain medical records and images prior to new patient visits (NPV). The adult clinic uses a traditional scheduling approach with an electronic template to mix new and return patients into a clinic schedule to maximize patient flow through the clinic session.

In the pediatric urology clinic, there are 5 fellowship-trained pediatric urologists that represent 3.9 full-time equivalents and two pediatric nurse practitioners. The pediatric urologists have a shared practice seeing the full range of pediatric urologic patients, while the nurse practitioners primarily see patients with 
the diagnoses of urinary tract infection and voiding dysfunction. Due to a longstanding interest in access improvement, the pediatric division has adopted a patient-centric approach to scheduling. In part, this is again due to the great distances involved for patients traveling to Salt Lake City for their care. This effort has led to evaluation of images (when possible) for patients prior to their clinic visit so appropriate follow-up imaging can be ordered for the same day as their new patient visit. A modified open access system was adopted 6 years ago wherein $60 \%$ of all new patient appointments are blocked until 7 days prior to allow faster access to new patient appointments.

The pediatric division also has two remote clinics that account for $3.5 \%$ of our total clinic appointments which are not included in this evaluation. Similarly, the adult clinic has 2 off-campus sites for clinic appointments that account for less than $10 \%$ of patient visits that are not included in this data.

In order to better understand the choices patients make for new patient visits, we felt that four data sets would be helpful:

1. The ratio of new patient visits to return patient visits, reported as the percentage of total visits that were new patient visits.

2. The average number of new appointments available each day.

3. A real-time telephone survey for patients who did not choose the first available appointment.

4. A three-month collection of schedule lag times.

These metrics were chosen to capture the extent of the self-deferring choices of patients, as well as the variation in the 2 practices. The crux of the study design was to collect data on why patients chose something other than the first available appointment. We expected to see a greater rate of self-deferral among the pediatric patients because of the nature of the diseases and the greater number of tests that would be ordered prior to the initial visit. The telephone surveys for both clinics were conducted during June 2013. We chose a three-month data collection from May-July, 2013 to smooth out any weekly variations. The data for delays include weekends even though no scheduling is performed on the weekends. To measure clinic access we calculated an average lag time-defined as the number of days from the date of the initial phone call until the date of the patient's visit-and an average lag time after deleting the patients who selfdeferred. IRB approval was not required for this study.

\section{Results}

The data are shown separately for the adult and pediatric parts of our practice to help readers understand our patient issues and how it may apply to other locations. The base capacity of the clinics is outlined in Table 1.

Three-week telephone survey data

Our telephone survey in the adult urology clinic (Table 2(a)) showed that a total of 19 patients (14\%) delayed their new patient visit. Two (2\%) were because of the physicians advice and $11(8 \%)$ were because of patient choice. Of concern is that $6(5 \%)$ chose not to wait and presumably sought care from another practice. 
Table 1. Adult and pediatric clinic scheduling data.

\begin{tabular}{lcc}
\hline & Adult Urology & Pediatric Urology \\
\hline Percent New Patients & $31 \%$ & $50 \%$ \\
Average New Patient Visits/Day on the Template & 10 & 15 \\
Emergent New Patients & 2 & \\
New Patients Worked Around the Scheduling Template & 3 & 15 \\
Total New Patients/Day & 15 & \\
\hline
\end{tabular}

Table 2. (a) Adult Clinic Data: Reasons patients did not accept the first available appointment; (b) Pediatric Clinic data: Reasons parents did not accept the first available appointment.

(a)

\begin{tabular}{ccccc}
\hline Number of Calls & $\begin{array}{c}\text { MD advised } \\
\text { waiting* }\end{array}$ & Patient choice to wait & $\begin{array}{c}\text { Did not accept visit with } \\
\text { PA/APRN }\end{array}$ & $\begin{array}{c}\text { Total number not want to wait } \\
\text { delaying appt. }\end{array}$ \\
\hline 132 & 2 & 8 & 3 & 6 \\
$\%$ of Total & $2 \%$ & $6 \%$ & $2 \%$ & $5 \%$ \\
\hline
\end{tabular}

${ }^{*}$ When a provider asks that the patient wait longer that the next available appointment because of the patient's diagnosis.

(b)

\begin{tabular}{|c|c|c|c|c|c|c|c|}
\hline Number of calls & $\begin{array}{c}\text { MD advised } \\
\text { waiting }\end{array}$ & $\begin{array}{c}\text { Radiology imaging } \\
\text { combined with } \\
\text { APRN appt. }\end{array}$ & $\begin{array}{l}\text { Radiology imaging } \\
\text { combined with a } \\
\text { MD appt. }\end{array}$ & $\begin{array}{c}\text { Waited for a } \\
\text { specific provider } \\
\text { or clinic location }\end{array}$ & $\begin{array}{l}\text { Needed appt. } \\
\text { w/ surgery the } \\
\text { following day }\end{array}$ & $\begin{array}{l}\text { Parents chose } \\
\text { to wait }\end{array}$ & $\begin{array}{l}\text { Total number } \\
\text { delaying appt. }\end{array}$ \\
\hline 305 & 30 & 25 & 21 & 17 & 2 & 38 & 133 \\
\hline$\%$ of total & $10 \%$ & $8 \%$ & $7 \%$ & $6 \%$ & $1 \%$ & $12 \%$ & $44 \%$ \\
\hline
\end{tabular}

*When a provider asks that the patient wait longer than the next available appointment because of the patient's diagnosis.

The results of the survey in the pediatric urology clinic are shown in Table 2(b). More categories of answers were documented in the pediatric survey, reflecting the complexities of the modified open access patient-centric scheduling. Pediatric patients are frequently referred as newborns but the optimal time to see them is months later. For example, a patient with an undescended testis may be discovered and referred to a urologist shortly after birth, but is not usually seen until after the first six months of life during which spontaneous descent of the testis is common.

Additionally, the effort of the pediatric urologists to perform follow-up imaging on the same day as the new patient visit is also noted as a reason for delays.

In our pediatric population, 133 parents (44\%) delayed their new patient visits. Of those, 76 ( $25 \%$ of the total) were advised by our staff to defer for specific medical and logistical reasons. Fifty-five parents ( $18 \%$ of the total) chose an appointment sometime after the first available appointment (12\% chose to wait for unspecified reasons and $6 \%$ waited for a specific provider).

Three-month appointment lag data:

In the adult urology clinic, Figure 1 shows the time between the patient's phone call for a NPV and the time the appointment occurred for each distinct patient, measured in days. The average lag time for all of the adult providers was 


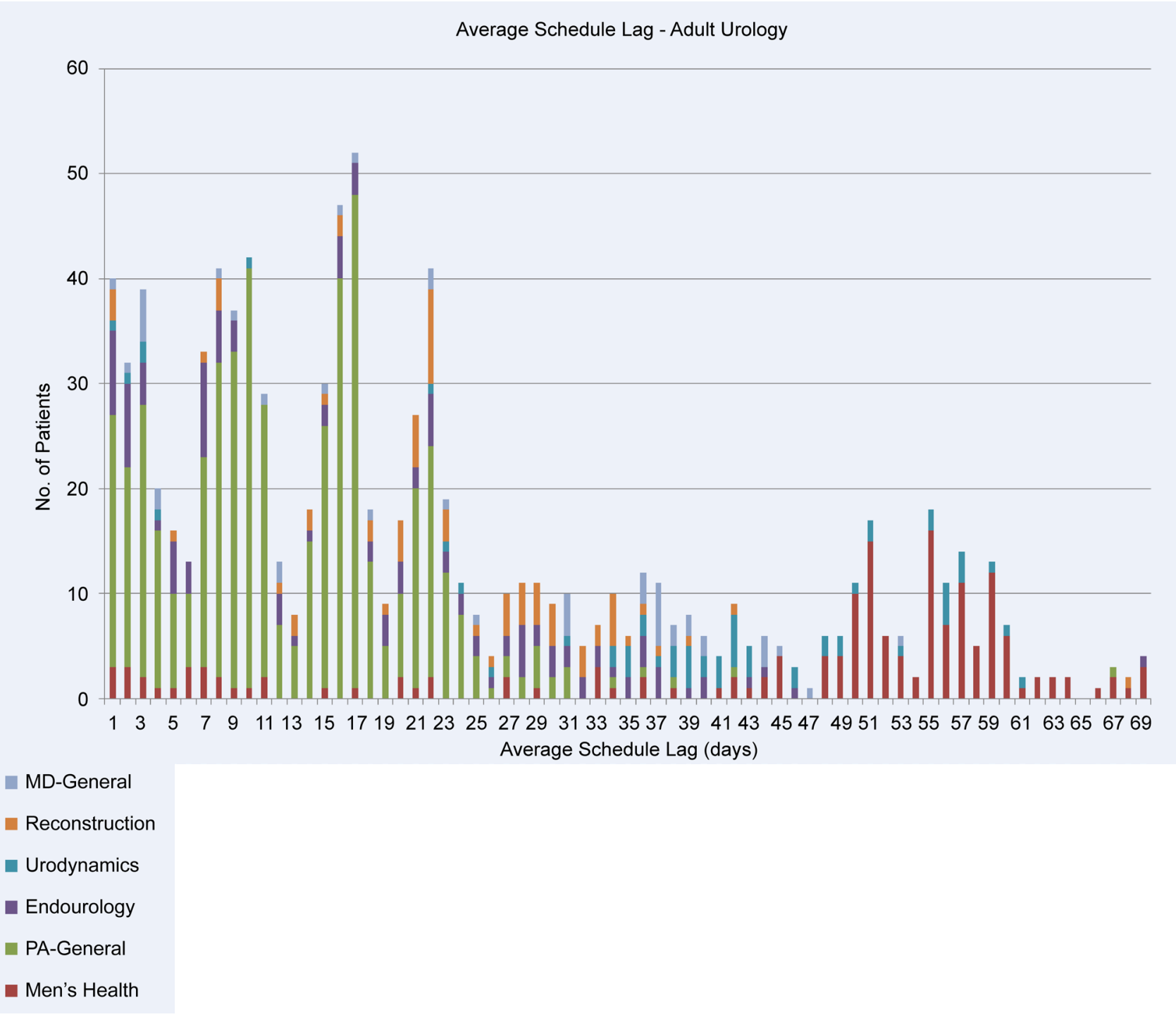

Figure 1. Average schedule lag for adult urology.

24.4 days. This figure also shows the inherent variability among the practitioners based on the nature of their subspecialty practices. In the pediatric urology clinic, the average schedule lag was 28.0 days (Figure 2).

Both of the figures illustrate the long lag time "tail" including patients who chose not to take the first available appointment. This long tail introduces a substantial bias in the calculations for average patient lag time, or any other currently used metric. This in turn reflects unfavorably on a practice that can only control some portion of patient decisions.

\section{Discussion}

Most clinic access studies are performed in primary care settings or in specialties with closed access such as the Veterans Administration system or within a single health insurance plan [5] [6] [7] [8] [9]. These studies are helpful but often not applicable to open system specialties or subspecialties. We sought to understand 


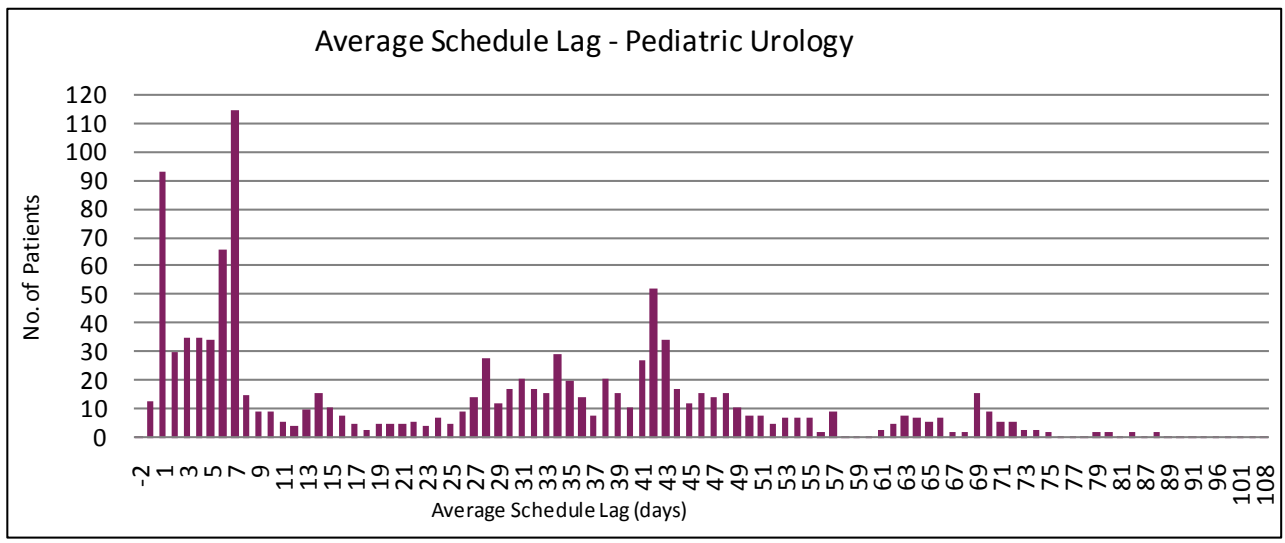

Figure 2. Average schedule lag for pediatric urology.

the new patient access within our community to better understand new patient access to urology clinics and how this knowledge might be applied more generally.

We focused upon one lightly studied aspect of patient access: Why the first available appointment was not accepted? Our hope was that this insight would help us find which portion of access was within the providers' control within our urology clinics and which portion was not.

In our pediatric division the patient-centric approach to scheduling has been responsible for $26 \%$ of the total new patient appointments requested being deferred beyond the first available appointment. And in some cases, this may be many days or weeks beyond. By combining the NPV with the imaging studies, we are able to minimize the number of return appointments required for the care of these frequently complex patients and minimize the time and expense that would be required for them, especially those who travel from a great distance. This approach simultaneously preserves more clinic appointments available for other new (and return) patients. But it does so at a cost of skewing the access metrics by which our practice is judged. A similar finding occurs on the adult side, but to a lesser degree.

Lag time calculations are greatly affected by patients who choose to wait. Since this difference is patient-controlled, it does not seem reasonable to measure clinic efficiency with the skewed data. When measured in the two separate practices that we studied, approximately $14 \%$ and $18 \%$ of patients chose to self-defer their NPV, which may substantially change the schedule lag data. Since it is impractical for each scheduling office to collect this data, it may be reasonable to extrapolate the data from this study to more accurately gauge their clinic efficiency and new patient schedule lag time. Our data suggests that in the neighborhood of $15 \%-20 \%$ of the lag time is the patient responsibility and $80 \%-85 \%$ is within the control of the clinic and providers.

In our adult data, an additional finding raised concerns that may affect the success of a practice. Five percent of the patients who called and did not accept the first available appointment offered indicated that they looked to another urology group in our region for a more timely appointment. In a surgical specialty 
practice, where new patients are important to continued viability, this represents a steady drain of these valuable patients. This did not happen in our pediatric survey presumably because there are no other pediatric urology specialists in our geographic area, but this could be very different in a metropolitan area with competing practices.

Our study has some limitations:

1. We only collected the data on appointment delays for 3 weeks because this was very labor intensive to collect. This may not be a large enough sample to be highly accurate, although for our purposes, we felt it did correctly reflect patient trends.

2. We had no way to verify if the reasons given on the phone were accurate, nor did we have any way of eliminating duplicate calls from any given patient.

3. Because of the timing of our study, we did not identify any seasonal variations which would not have been apparent in our data set.

4. With our adult providers in different subspecialties, schedule lag times may have more to do with subspecialty differences and the urgency of the diagnosis than the clinic efficiencies. For example, there was a much longer delay for the men's sexual health expert because of the great demand, the provider's reputation and expertise, and the non-urgent nature of the patient diagnoses. By contrast, the providers who see patients with acute kidney stones or hematuria are seen with a shorter lag time.

5. Finally, by combining the numbers of the urologists and the PA/APRNs, the data may be skewed in ways that we don't understand. For example, the urologists naturally spend less time in clinic because a substantial portion of their week's work is done in the operating room, whereas these PA/APRNs spend most of their working time in the clinic.

\section{Conclusion}

By conducting a telephone survey, we found that $14 \%$ percent of adult patients and $18 \%$ of parents of pediatric patients chose to wait longer that the first available appointment in our study. Further, an additional $26 \%$ of pediatric patients were directed by the physician to defer their appointments for either sound medical reasons or in an attempt to economize the time and money spent by those patients. Consequently, providers and clinic staff control only $80 \%-85 \%$ of the factors that affect new patient access to a urology clinic. We believe this offers support for the argument that providers should not be penalized for those aspects of new patient access that area out of their control.

\section{References}

[1] Snow, B.W., Cartwright, P.C., Everitt, S., Ekins, M., Maudsley, W. and Aloi, S. (2009) A Method to Improve Patient Access in Urological Practice. The Journal of Urology, 182, 663-667. https://doi.org/10.1016/j.juro.2009.04.003

[2] Jones, W., Elwyn, G., Edwards, P., Edwards, A., Emmerson, M. and Hibbs, R. (2003) Measuring Access to Primary Care Appointments: A Review of Methods. BMC Family Practice, 4, 8. https://doi.org/10.1186/1471-2296-4-8 
[3] Pickin, M., O'Cathain, A., Sampson, F.C. and Dixon, S. (2004) Evaluation of Advanced Access in the National Primary Care Collaborative. British Journal of General Practice, 54, 334-340.

[4] Smoller, M. (1992) Telephone Calls and Appointment Requests. Predictability in an Unpredictable World. HMO Practice, 6, 25-29.

[5] Murray, M. and Tantau, C. (2000) Same-Day Appointments: Exploding the Access Paradigm. Family Practice Management, 7, 45-50.

[6] Blumenfeld, A. and Tischio, M. (2003) Center of Excellence for Headache Care: Group Model at Kaiser Permanente. Headache, 43, 431-440. https://doi.org/10.1046/j.1526-4610.2003.03087.x

[7] Bauer, M.S., McBride, L., Shea, N., Gavin, C., Holden, F. and Kenall, S. (1997) Impact of an Easy-Access VA Clinic-Based Program for Patients with Bipolar Disorder. Psychiatric Services, 48, 491-496. https://doi.org/10.1176/ps.48.4.491

[8] Aiello, K. (2005) Open Access Appointing in Army Primary Care Clinics. Military Medicine, 170, 370-374. https://doi.org/10.7205/MILMED.170.5.370

[9] Joyce, G.F., Kapur, K., Van Vorst, K.A. and Escarce, J.J. (2000) Visits to Primary Care Physicians and to Specialists under Gatekeeper and Point-of-Service Arrangements. The American Journal of Managed Care, 6, 1189-1196.

[10] Murray, M. and Berwick, D.M. (2003) Advanced Access: Reducing Waiting and Delays in Primary Care. JAMA, 289, 1035-1040.

https://doi.org/10.1001/jama.289.8.1035

[11] UHC Ambulatory Care Quality and Accountability Study, Web Conference, February 3, 2015.

\section{Submit or recommend next manuscript to SCIRP and we will provide best} service for you:

Accepting pre-submission inquiries through Email, Facebook, LinkedIn, Twitter, etc. A wide selection of journals (inclusive of 9 subjects, more than 200 journals)

Providing 24-hour high-quality service

User-friendly online submission system

Fair and swift peer-review system

Efficient typesetting and proofreading procedure

Display of the result of downloads and visits, as well as the number of cited articles

Maximum dissemination of your research work

Submit your manuscript at: http://papersubmission.scirp.org/

Or contact oju@scirp.org 